\title{
Estimation of mechanical resistance of lakeside Phragmites stands
}

\author{
Wolfgang Ostendorp \\ Fakultät für Biologie, Universität Konstanz, Postfach 5560, D-78434 Konstanz, Germany
}

\begin{abstract}
The power of resistance of reed stands against mechanical impact by waves and drifting matter is assessed using the mechanical properties of the stem wall (modulus of elasticity, breaking stress), the dimensions of the stem's cross section (diameter, momentum of inertia), and the culm density. The power of resistance of an individual stem (pmr) was found to be proportional to the bending stiffness $\left(M_{\mathrm{E}}\right)$ and to the breaking strength $\left(M_{\mathrm{S}}\right)$ in the internode position where maximum deflection or breaking occurs. The power of mechanical resistance of reed stands (PMR) was found to be proportional to the sum of individual $M_{\mathrm{E}}$ values (or $M_{\mathrm{S}}$ values, respectively) per unit surface $\left(1 \mathrm{~m}^{2}\right)$. Two predictive models, based on the pmr and the PMR values were tested using mechanically damaged stands in the field; the pmr model fits observed values in 70-90\% of all cases (damaged culms), the PMR model explains $53-67 \%$ of the variability in percentage of damaged biomass.
\end{abstract}

Keywords: Lake Constance; Littoral reeds; Mechanical damage; Wave action; Drifting matter; Phragmites australis

\section{Introduction}

In many central European lakes, a remarkable regress of lakeside reedbelts (Phragmites australis (Cav.) Trin. ex Steud., Poaceae) has been observed during the last 30 years. One important factor is mechanical damage to the reed front by wave action, and by waves loaded with floating rubbish, driftwood and wash of filamentous algae (Ostendorp, 1989). The culms are bent down by such impacts, and the leaves may be ripped up or stripped off. If the culm is pressed below the water surface, the leaves are not able to photosynthesise (Rodewald-Rudescu, 1974, p. 81). Hence, the transport of assimilates to the rhizomes is severely reduced. In many cases the culms are broken at their base. Then the central cavity of the internode and the aerenchyma are filled with water. As the diffusion rate of oxygen is much lower in water than in air, oxygen supply to the underground organs is inhibited. 
The resulting oxygen deprivation in the rhizome tissue sets up an energy-consuming anoxic metabolism, which may lead to a die-off of parts of the rhizome complex within a few days (Steinmann and Brändle, 1984; Studer and Brändle, 1984; Brändle, 1991).

The degree of damage to lakeside reed stands is determined by the capability of the reed to withstand the external forces (waves + drifting matter). If the acting forces are great enough, the mechanical tolerance of the culm will be exceeded, and the culm will fail, resulting in some kind of damage, as described above. Binz-Reist (1989) attempted to put the interaction of wind and wave forces with the resistance of the stem into a mathematical form. His model is based on mathematical concepts used in civil engineering. Only basic simplifications of the real forces and mechanical properties of the reed culm were made. The model allows computation of the critical wave height (i.e. wave energy, as $E_{\text {wave }} \approx H^{2}$ ) at which a culm fails. Whether a culm fails or not depends on numerous factors which must be quantified to take advantage of this model. Many of the input variables cannot be measured with sufficient precision. The author admits (p. 250), that the model calculates relative differences in tolerable wave height rather than absolute values. Hence, its practical value for quick and simple estimation of mechanical impacts to lakeside reeds and their consequences for the plants' survival is doubtful.

In this paper, a simple stochastic model is proposed that allows assessment of the mechanical susceptibility of a reed stand, based on the mechanical properties of the stem wall tissue, the dimensions of the stem's cross section, and the stand structure. It is thereby possible to compare reed stands in the field with respect to their potential susceptibility to the impact of waves or waves + drifting matter. The validity of the model is tested using mechanically damaged Phragmites stands on the shores of Lake Constance-Untersee.

\section{Study site}

Lake Constance-Untersee is the western part of the Lake Constance system (SW Germany, Switzerland, $8^{\circ} 51^{\prime} 37^{\prime \prime}-9^{\circ} 08^{\prime} 23^{\prime \prime} \mathrm{E}, 47^{\circ} 38^{\prime} 45^{\prime \prime}-47^{\circ} 44^{\prime} 17^{\prime \prime} \mathrm{N}$ ), a shallow (mean depth $12.5 \mathrm{~m}$ ), eutrophic lake with broad shelves and extended reed belts which cover about $31 \%$ (about $295 \mathrm{ha}$ ) of the eulittoral area, or $54 \%$ of the total shore length within German territory (Ostendorp, 1991). Of the eulittoral reed area, $99.7 \%$ is comprised of monospecific stands of Phragmites australis, a perennial grass with thick culms, about 6-13 $\mathrm{mm}$ in diameter at the culm base and about $2.5-4.5 \mathrm{~m}$ in height. The sublittoral zone is covered with submerged macrophytes, mainly Chara spp., Potamogeton spp. and filamentous algae (e.g. Cladophora sp.) (Lang, 1981). In late summer and autumn, when the water level is low and strong winds occur, the mats of senescent submerged plants are uprooted and washed ashore (Ostendorp, 1992). The water level is high in summer as a result of ice and snow melting in the inner alpine region, and low in winter. In summer all lakeside reeds are submerged, and in winter the greater part of them become dry. The most frequent water level mark within the course of the year is near the ground level of the lakeside reed front. Westerly winds prevail in the Lake Constance region, changing from WNW in spring and summer to WSW in winter. Strong winds and storms are rare, and occur mainly in the winter period when the water level is low. 


\section{Materials and methods}

The description of damaging factors and the response of the reed culms to mechanical impacts relies on field observations at Lake Constance-Untersee, both under fine and bad weather conditions and on shoreline mappings in late autumn that record the type and degree of mechanical damage to the reed front that took place the preceding season.

The measurement and evaluation of model parameters, bending stiffness and breaking strength, were taken from Binz-Reist (1989). The bending stiffness

$$
M_{\mathrm{E}}=E \times J
$$

can be regarded as the ratio of the bending momentum to the curvature of the stem induced by it. This ratio depends on mechanical properties of the stem wall material (modulus of elasticity, $E$ ) and geometric dimensions of the stem's cross section (momentum of inertia, $J$ ). The breaking momentum

$$
M_{\mathrm{S}}=\frac{1}{4} L \times F_{\mathrm{br}}
$$

is the breaking strength, which is proportional to the breaking force $F_{\mathrm{br}}$, perpendicular to the stem axis and to the distance between this force and each supporting point $1 / 2 L$, where $L$ is the distance between the supporting points. If written as

$$
M_{\mathrm{S}}=\frac{1}{2} S \times J \times D^{-1}
$$

$M_{\mathrm{S}}$ is a function of the properties of the stem wall material (breaking stress, $S$ ), of the stem diameter $D$, and of the momentum of inertia, $J$, of the stem cross section. These formulae refer to the 'three-point' testing device (two supporting points, single force action in the middle between the supporting points) used by Binz-Reist (1989) (Fig. 1). All measurements in this paper refer to fully grown stems or stem sections without leaves and leafsheaths.

The model proposed in Section 4.3 was tested on individual culms within a stand (Test 1) and on monospecific Phragmites stands (Test 2). Some characteristic features of the test stands are given in Table 1 . The stands were damaged partly by storm-induced waves and partly by drifting matter during late summer. Stand structure measurements and sampling were performed in late autumn when the water level had dropped. The test areas were carefully selected according to their homogeneity.

\subsection{Test I}

The culms were divided into four groups: (A) upright culms (about $0-30^{\circ}$ deviation from the vertical axis); (B) bent culms (about $30-70^{\circ}$ ); (C) culms bent down to the ground (about $70-90^{\circ}$ ); (D) broken culms. Representative culms were cut off at ground level and processed in the laboratory. The diameter of the bent or broken internode was measured after drying $\left(60^{\circ} \mathrm{C}, 2\right.$ days); for upright culms a corresponding internode was taken. An undamaged double-internode piece was cut out just above the bent or broken internode, and 

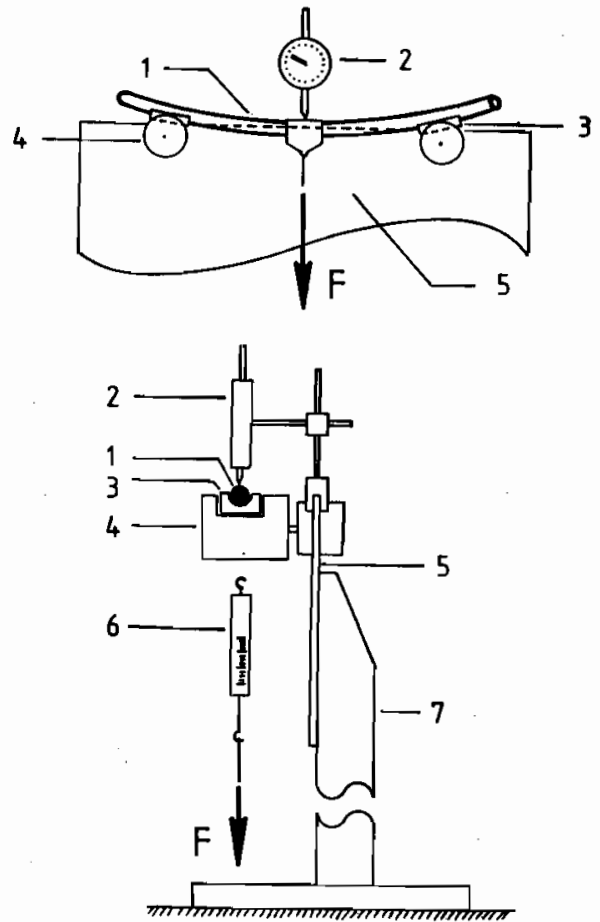

Fig. 1. Testing device (above, front view; below, side view): 1, double internode piece; 2 , distance gauge (0-10 $\mathrm{mm}, \Delta=0.01 \mathrm{~mm}$ ); 3 , wooden adapters for the double internode pieces; 4 , revolving metal cylinders with a clamping attachment to the aluminium plate $(5) ; 5$, stable aluminium plate; 6 , calibrated spring balance; 7 , stand. Adapted from Binz-Reist (1989).

bending stiffness $\left(M_{\mathrm{E}}\right)$ and breaking strength $\left(M_{\mathrm{S}}\right)$ were measured using the device described by Binz-Reist (1989, pp. 455-460) (Fig. 1). The cumulative $M_{\mathrm{E}}$ and $M_{\mathrm{S}}$ frequency distributions of groups A, B, C and D were tested pairwise using the KolmogorovSmirnov test under $H_{0}$ : the two empirical frequency data sets $F(P)$ and $G(P)$, $P=P\left\{M_{\mathrm{E}}, M_{\mathrm{S}}\right\}$ belong to the same distribution. $H_{0}$ was refused if the test statistic $\delta=\max |F(P)-G(P)|$ exceeded $\delta_{\text {cril }}$.

\subsection{Test 2}

To test the model at stand level, a shore section had to be found which fulfilled the following specifications: (a) a monospecific Phragmites stand was present, which (b) was seriously damaged by waves perpendicular to the shoreline, charged with drifting matter, (c) had a relatively wide range of stand structural properties (culm density, stem diameter), and (d) showed insignificant alongshore variation of the mechanical impact. Only one location was found at Lake Constance that satisfied these requirements fairly well. Twenty test plots of $1 \mathrm{~m}^{2}$ each were selected randomly. The culms were clipped at ground level and processed in the laboratory as described above. The percentage of damaged culms (class $\mathrm{C}+\mathrm{D}$ ) was related to the model parameters (see Section 4.3) of each test plot. 


\section{Results}

\subsection{Types of mechanical load to lakeside reed belts}

Field mappings which were run over 3 years (partly published in Ostendorp, 1992) showed that the different types of mechanical threat to lakeside reeds in Lake ConstanceUntersee can be grouped according to their frequency and significance as follows: waves charged with drifting matter $>$ wave action only $>$ hail storm $>$ resting birds $>$ recreational activities $>$ professional fishing $>$ wind action only. Here, resting birds are flocks of starlings (Sturnus vulgaris L.), recreational activities are swimming, surfing and boating, and professional fishing is eel-basket fishing.

The most abundant drifting matter consists of uprooted submerged plants and filamentous algae (Ostendorp, 1992), followed by mats of broken Phragmites stems from the previous years and a wide range of solid rubbish. Mechanical damage due to snow cover, drifting ice, trampling (cattle, holiday makers), and motor boat generated waves has been proved

Table 1

Characteristics of the test stands MOD I, II and III (monospecific Phragmitetum typicum (sensu Lang 1967 , 1990) on nutrient-poor lake marl sediments)

\begin{tabular}{|c|c|c|c|}
\hline & MOD I & MOD II & MOD III \\
\hline Culm density (no. $\mathrm{m}^{-2}$ ) & 28.1 & 34.0 & 32.5 \\
\hline Biomass dry weight $\left(\mathrm{g} \mathrm{m}^{-2}\right)$ & 1651 & 745 & 1427 \\
\hline \multicolumn{4}{|l|}{ Length $^{\mathrm{a}}(\mathrm{m})$} \\
\hline PSh & 3.93 & 2.71 & 3.69 \\
\hline SSh & 2.75 & 1.79 & 2.56 \\
\hline \multicolumn{4}{|l|}{ Stem diameter ${ }^{b}(\mathrm{~mm})$} \\
\hline PSh & 8.96 & 7.51 & 9.19 \\
\hline SSh & 7.16 & 5.11 & 6.82 \\
\hline \multicolumn{4}{|l|}{ Culm biomass dry weight ( $\mathrm{g}$ ) } \\
\hline PSh & 73.6 & 35.6 & 69.6 \\
\hline SSh & 27.3 & 11.1 & 24.4 \\
\hline \multicolumn{4}{|c|}{ Modulus of elasticity $E\left(\mathrm{kN} \mathrm{cm}^{-2}\right)$} \\
\hline PSh & 1834 & 1601 & 2285 \\
\hline SSh & 1142 & 892 & 1736 \\
\hline $\begin{array}{l}\text { Cause and kind of mechanical } \\
\text { damage }\end{array}$ & $\begin{array}{l}\text { Waves in autumn; } \\
\text { damaged culms broken } \\
\text { in the } 5 \text { th or } 6 \text { th } \\
\text { internode }\end{array}$ & $\begin{array}{l}\text { Waves in July: } \\
\text { damaged culms bent } \\
\text { down to the water } \\
\text { surface or broken in the } \\
\text { 2nd or 3rd internode }\end{array}$ & $\begin{array}{l}\text { Waves in autumn; } \\
\text { damaged culms bent } \\
\text { down to the water } \\
\text { surface or broken in the } \\
\text { 3rd or 4th internode }\end{array}$ \\
\hline Damaged culms (\%) & 25.0 & & \\
\hline Broken & & 32.1 & 8.5 \\
\hline Bent down & & 32.6 & 20.5 \\
\hline Damaged biomass (\%) & 13.7 & & \\
\hline Broken & & 22.1 & 4.4 \\
\hline Bent down & & 27.7 & 11.4 \\
\hline
\end{tabular}

${ }^{\text {aPanicle included. }}$

bHalf length of the stem.

PSh, panicle-bearing primary shoots; SSh, flowerless secondary shoots. 
to be of little importance in Lake Constance. Normally, small pieces of drift wood and floating rubbish slowly invade the lakeside reeds, being gently moved by the breeze and by waves and littoral currents and become captured between the Phragmites culms at some distance from the open lake. Larger fragments accumulate in small aisles and bights just in front of the closed reed stand. In sparse reeds, mats of filamentous algae (e.g. Cladophora sp.) grow between the culms. Generally, there is no significant injury to the reeds unless the wash is agitated by waves and breakers.

During storms, senescent submerged macrophytes, often overgrown with filamentous algae, are uprooted, transported by the shoaling waves and thrown against the reed front. When the clumps reach the reed front, each wave crest lifts up the drifting matter which is jammed onto the culm or between the leaves. When the wave trough arrives, the water moves back, but the culm is not able to push back the attached matter. Thus, the wet material hangs down from the subaerial culm, exerting an additional gravitational force on it. If bigger clumps are attached, the culm cannot right itself between two wave crests. Any higher wave crest is then able to push the clump higher onto the culm which becomes bent down. Binz-Reist (1989, p. 169) emphasises that the impact of loose drifting matter is more serious than that of material which does not become attached to the reed culm.

\subsection{Response of individual Phragmites culms}

Individual $P$ hragmites culms react to the impact of waves plus drifting matter in different ways (Fig. 2).

(1) Elastic oscillations of the culm in harmony with the frequency of the incoming waves (Fig. 2a). As the wave crest reaches the location, the culm is bent along the propagation direction of the wave. In the wave trough, the forces of elastic recovery of the deformed culm together with the low pressure of the back flow of the water result in a lakeward bending, whereby solid drifting matter is repulsed. This is the case under low energy conditions (low wave height and/or low mass of drifting matter) and at low or moderate water depths.

(2) Elastic bending of the culm under high energy conditions in deep water. The stem with its leaves is bent down below the water surface. Thus the drifting matter (especially solid matter) is swept across this culm, that can right itself again (Fig. 2b). By this process only the leaves get injured. They may be torn or stripped off. Culms that are damaged in this way will wither earlier in the season than intact ones.
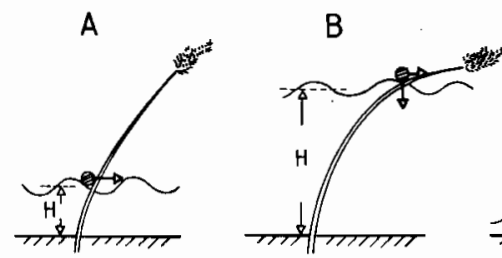

[

0

Fig. 2. Response of individual Phragmites stems to mechanical impacts by waves + drifting matter under different energy and water depth $(H)$ conditions. (A) Upright stems, elastic oscillating motion; (B) elastic bending of the stem; (C) plastic bending of the stem below the water surface; (D) breaking of the stem at its base. See text for explanations. 
(3) Plastic bending, which typically occurs under high energy conditions and in shallow water: the drifting matter bends the culm down under the water surface. It does not travel across, but settles down onto the leaf-bearing parts of the culm (Fig. $2 \mathrm{c}$ ). The culm is unable to right itself, even when the wave trough passes by. Most of the photosynthetic biomass is submerged or stripped off.

(4) Breaking of the stem at its base, due to the same procedure as described above. The upper part of the culm is disconnected from the roots and dies off. The central cavity and the aerenchyma of the remaining stubble is filled with water (Fig. 2d).

All these types of response can be observed in moderately affected stands composed of a broad range of culm lengths and diameters. In a dense Phragmites stand, interactions between the culms occur, e.g. the joint repulse of drifting matter, or the support of weaker and thinner culms by stronger ones.

\subsection{Formulation of a model}

The degree of damage to an individual culm ( $\mathrm{dmd}$ ) can be described by the types of response discussed above: broken $>$ bent down to the ground $>$ bent down to the water surface $>$ more or less upright.

Phragmites is a clonal grass with its aerial culms interconnected by rhizomes. The fully grown culms export nutrients, assimilates and oxygen to the underground organs. It is assumed that, on a yearly basis, the nutrient and carbohydrate balance influence the performance of the following season's shoot generation. The degree of damage to a reed stand (DMD) with respect to its nutrient economy and oxygen supply can be quantified by the percentage of severely damaged ( class $C+D$ ) culms. Field observations have revealed that the DMD is the result of many factors, which to a great extent vary independently. Inspected at an ecosystem level, the degree of damage to reeds along the lake shore cannot be described other than by a stochastic model (Fig. 3). To simplify this complex situation, we can say that

$\mathrm{DMD}=$ wave energy + abundance of drifting matter

- power of mechanical resistance (PMR)

The wave energy input per hour and running metre at the transitional line between deep and shallow water waves depends on wind velocity, fetch and shore exposure relative to the orthogonals of the incoming waves (Carter, 1988; Binz-Reist, 1989). While the wave travels over the shore platform, it loses energy by friction owing to the hydraulic roughness of bottom sediments and submerged vegetation. Losses are high under low water conditions. Many of these factors vary with season (Fig. 3).

The energy that drifting matter can transmit to an individual reed culm depends on its density, mass, and on its acceleration by the wave motion. As far as macrophyte mats are concerned, their abundance should be positively correlated with the total sublittoral area in front of the reed belt, and the standing crop per unit surface. Whether a clump of a submerged plant is uprooted by the surf or not also depends on the water level, the state of development of the plant (e.g. senescence) and the species-specific form drag (Fig. 3).

The formula of Binz-Reist (1989) proposes that the mechanical resistance is a function of the mechanical properties of the Phragmites stem wall material (modulus of elasticity 


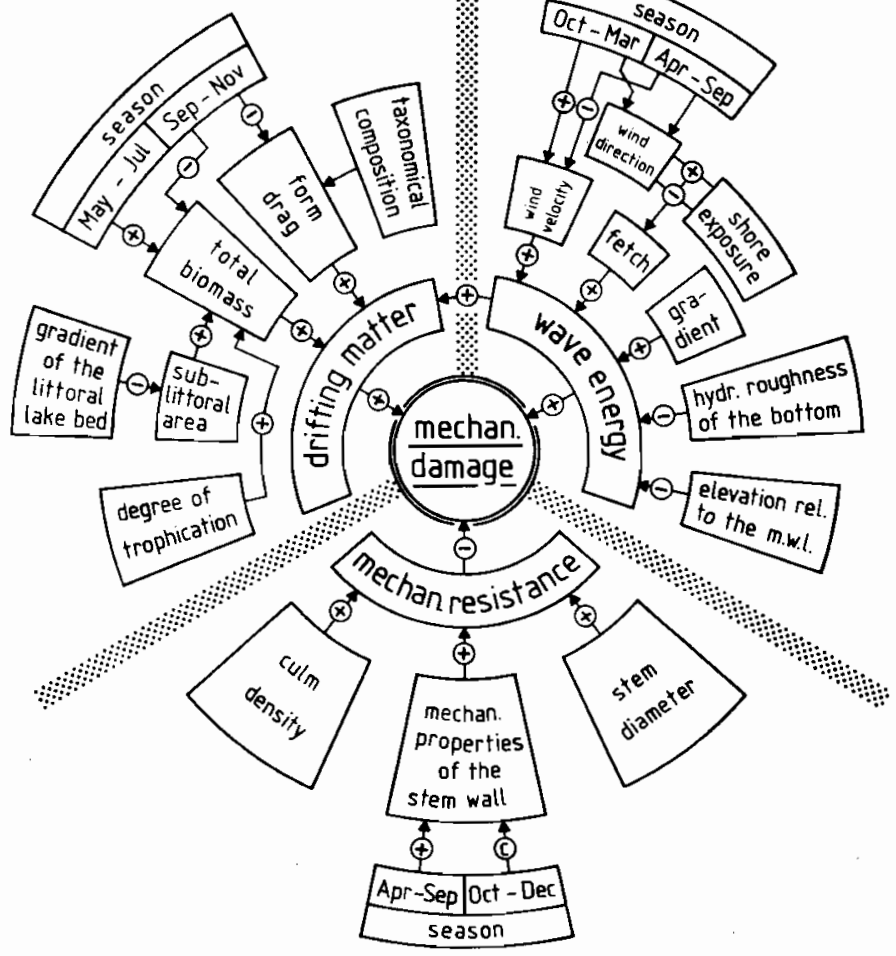

Fig. 3. Factors affecting the damage to lakeside reeds in Lake Constance-Untersee: + , accentuating influence; - , weakening influence; $c$, constant, time-independent influence; m.w.l., mean water level.

$E$, breaking stress $S$ ) and the cross sectional dimensions (diameter $D$, momentum of inertia $J)$. $E$ and $S$ vary with season, being highest from August to October (unpublished data). For an individual culm these parameters give the bending stiffness $M_{\mathrm{E}}$ and the breaking strength $M_{\mathrm{S}}$ according to Eqs. 1 and 2. Given a constant $M_{\mathrm{E}}$ value of a stem section, the deflection is proportional to the forces exerted by the drifting matter upon it. $M_{\mathrm{S}}$ represents the maximum force that a culm can withstand before it fails. In a reed stand area of $1 \mathrm{~m}^{2}$, a group of culms can absorb greater forces simultaneously without failing than can a single culm, or, if a constant mass of ( solid) drifting matter is simultaneously washed by constant waves against a number of culms of given mechanical properties, the deflection (or degree of damage) to each culm should be inversely proportional to this number. Though there are important differences between solid drifting matter (e.g. pieces of wood) and clumps of filamentous algae or waterplants, it is assumed that these relations will be valid even in the latter case, especially when the water depth is low and the culm density is high.

Hence, it is reasonable to accept that the power of mechanical resistance of an individual stem (pmr) is proportional to the bending stiffness or the breaking strength

$$
\mathrm{pmr} \approx M, M=M\left\{M_{\mathrm{E}}, M_{\mathrm{S}}\right\}
$$


and that the power of mechanical resistance of a reed stand (PMR) is the sum of individual pmr values per unit area $A$

$$
\mathrm{PMR} \approx 1 / A \sum M_{i}, M_{i}=M_{i}\left\{M_{\mathrm{E}, i}, M_{\mathrm{S}, i}\right.
$$

\subsection{Testing the model at the level of individual culms}

The test areas were the stands MOD I, MOD II and MOD III (Table 1) at the end of the growing season. It was assumed that, within a limited area of about $10 \mathrm{~m}^{2}$ along the shoreline, the forces exerted by waves and drifting matter had been the same for each culm. The aspect of the stand, the amount of drifting matter deposition, and the direction of incoming waves support this assumption. Thus, the dmd should depend only on the pmr of the individual stem.

If this holds true, there should exist a critical value $M_{\mathrm{E}, \text { crit }}\left(\right.$ or $\left.M_{\mathrm{S}, \text { crii }}\right)$ for which

each stem $i$ with $M_{\mathrm{E}, i}<M_{\mathrm{E}, \text { crit }}\left(M_{\mathrm{S}, i}<M_{\mathrm{S}, \text { crit }}\right)$ is damaged

(in the described manner: class B, C or D)

and

each stem $i$ with $M_{\mathrm{E} . i}>M_{\mathrm{E} . \text { crit }}\left(M_{\mathrm{S}, i}>M_{\mathrm{S}, \text { crit }}\right)$ is not damaged

in this manner (class $\mathrm{A}, \mathrm{B}$ or $\mathrm{C}$ )

$M_{\mathrm{E}, \text { crit }}\left(M_{\mathrm{S}, \text { crit }}\right)$ is the point on the abscissa at which there is a maximum distance $\delta$ between the cumulative frequency distributions of damaged and undamaged culms. The degree of congruence $\eta$ between this model and the field observations can be defined as

$$
\eta(\%)=\left(n_{1}+n_{2}\right) / n_{t} \times 100 ; \quad n_{1}+n_{2}+n_{3}+n_{4}=n_{t}
$$

where $n_{1}$ is the number of damaged culms with $M_{\mathrm{E}, i}<M_{\mathrm{E}, \text { crit }}, n_{2}$ is the number of undamaged culms with $M_{\mathrm{E}, i}>M_{\mathrm{E}, \text { crit }}, n_{3}$ is the number of damaged culms with $M_{\mathrm{E}, i}>M_{\mathrm{E}, \text { crit }}$ and $n_{4}$ is the number of undamaged culms with $M_{\mathrm{E}, i}<M_{\mathrm{E}, \text { crit }}$

If the model reflects reality perfectly, then all cases (culms) will be 'true', i.e. $n_{1}+n_{2}=n_{t}$, $n_{3}+n_{4}=0$. Figs. $4 \mathrm{a}-\mathrm{c}$ give three examples of the cumulative frequency distributions of $M_{\mathrm{E}}$ for damaged/undamaged culms and for different kinds of damage. The frequency distributions of each stand were tested pairwise for homogeneity by the Kolmogorov-Smirnov test. Table 2 shows that the frequency distributions are significantly different $(\alpha<0.001)$, except for the comparison B vs. C in MOD II. The greater the dmd, the lower the median of the $M_{\mathrm{E}}$ distributions in this class. The degree of congruence falls between $71 \%$ (MOD III: B vs. C) and $90 \%$ (MOD III: A vs. D), i.e. $71-90 \%$ of all culms were damaged according to their bending momentum (see Eq. 7). When the $M_{\mathrm{E}}$ data are grouped in only two classes, i.e. undamaged culms $(A+B)$ and damaged culms $(C+D)$, the degree of congruence is $82 \%$.

If $M_{\mathrm{S}}$ is used as a model parameter, $\eta$ lies similarly between 70 and $88 \%$. The background is that both parameters strongly depend on the internode diameter, which is the same for the computation of $M_{\mathrm{E}}$ and $M_{\mathrm{S}}$. So $M_{\mathrm{E}}$ and $M_{\mathrm{S}}$ are highly significantly correlated $(r=0.990, n=186, \alpha<0.001)$. 


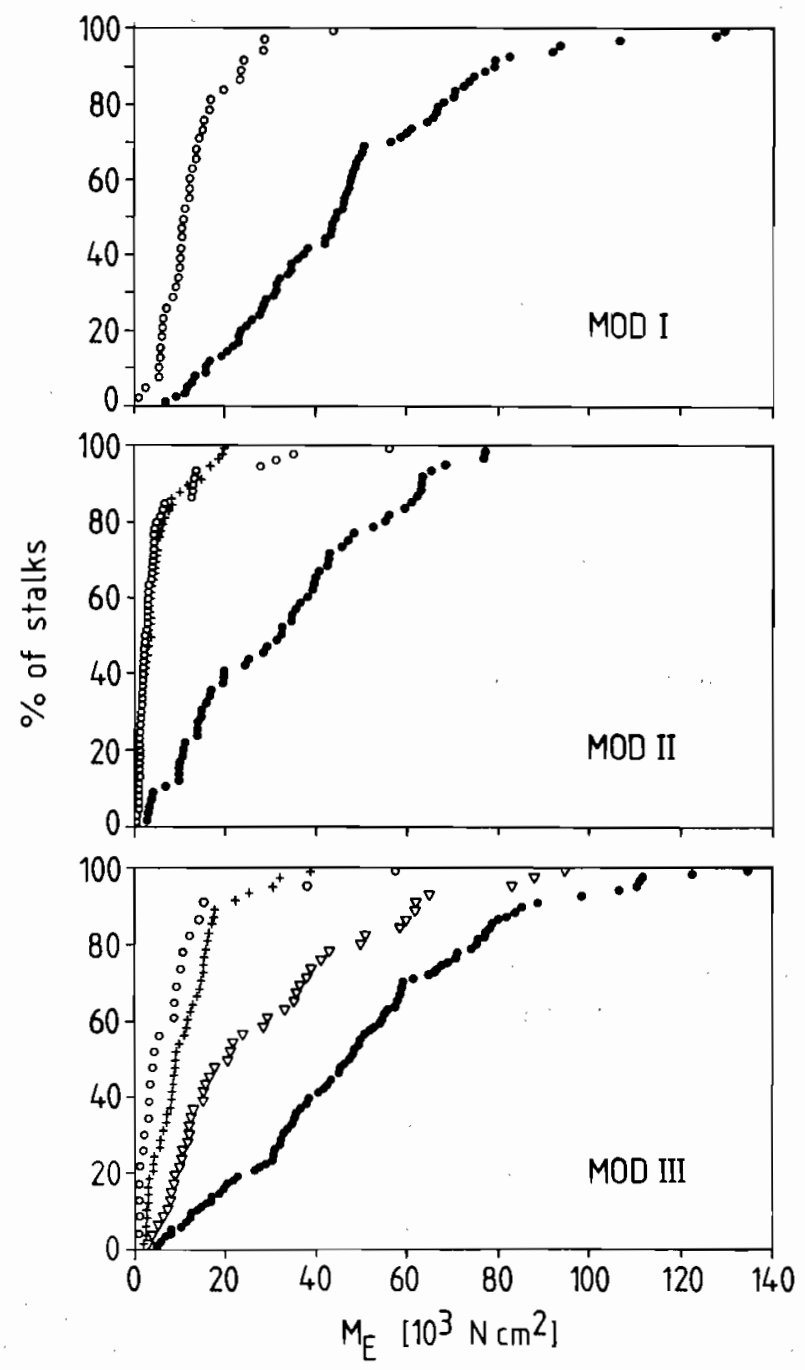

Fig. 4. Test of the pmr model on the level of individual stems: cumulative frequency distributions of bending stiffness $M_{1:}$ of individual stems. MOD, test stands ( see Table 1); $\bullet$, upright stems (class A); $\nabla$, bent stems (class B); + , stems bent down to the ground (class $\mathrm{C}$ );, , broken stems (class D).

From this test it is concluded that under field conditions, individual culms within a stand are damaged according to their bending stiffness or breaking momentum, i.e.

$$
\mathrm{dmd} \approx 1 / M, M=M\left\{M_{\mathrm{E}}, M_{\mathrm{S}}\right\}
$$

The field observations showed that secondary shoots ( $\mathrm{SSh}$ ) are damaged more often than primary shoots (PSh) (Table 3), because they are thinner, and exhibit lower moduli of elasticity (Table 1). 
Table 2

Statistical evaluation of the cumulative frequency distributions of the dmd classes A (upright stems), B (bent stems). C (stems bent down to the water surface) and D (broken stems) for the test stands MOD I, II and III (see Fig. 4)

\begin{tabular}{llllll}
\hline Test stand & $\begin{array}{l}\text { Comparison of } \\
\text { classes of } \\
\text { mechanical damage }\end{array}$ & $\delta_{\max }$ & $\begin{array}{l}M_{\text {E.crit }} \\
\left(\mathrm{kN} \mathrm{cm}^{2}\right)\end{array}$ & $\alpha$ & $\begin{array}{l}\eta \\
(\%)\end{array}$ \\
\hline MOD I & A vs. B & 0.71 & 22 & 0.001 & 85 \\
MOD II & A vs. B & 0.73 & 9 & 0.001 & 87 \\
& A vs. C & 0.74 & 7 & 0.001 & 87 \\
& B vs. C & 0.09 & 3 & $>0.1$ & 55 \\
MOD III & A vs. B & 0.33 & 28 & 0.001 & 67 \\
& A vs. C & 0.73 & 22 & 0.001 & 87 \\
& A vs. D & 0.79 & 18 & 0.001 & 90 \\
B vs. C & 0.42 & 19 & 0.001 & 71 \\
& B vs. D & 0.54 & 11 & 0.001 & 77 \\
& C vs. D & 0.28 & 5 & 0.01 & 64 \\
& A + B vs. C+D & 0.64 & 20 & 0.001 & 82 \\
\hline
\end{tabular}

$\boldsymbol{\delta}_{\max }$, maximum distance between two frequency distributions; $M_{\mathrm{E} . \mathrm{crit}}$, bending stiffness at which $\delta$ is at maximum; $\alpha$, level of significance for the nonparametric Kolmogorov-Smirnov test; $\boldsymbol{\eta}$, degree of congruence (see text for explanation).

Table 3

Percentage of mechanically damaged (dmd classes $C$ and D) and undamaged ( $A$ and B) primary shoots (PSh) and secondary shoots (SSh) in the test stands MOD 1, II, and III

\begin{tabular}{|c|c|c|c|c|c|c|}
\hline & \multicolumn{2}{|c|}{ MOD I } & \multicolumn{2}{|c|}{ MOD II } & \multicolumn{2}{|c|}{ MOD III } \\
\hline & PSh & SSh & PSh & SSh & PSh & SSh \\
\hline Upright (A) and bent (B) & 96 & I4 & 64 & 6 & 99 & 35 \\
\hline $\begin{array}{l}\text { Bent down to the water } \\
\text { surface (C) and broken (D) }\end{array}$ & 4 & 86 & 36 & 94 & 1 & 65 \\
\hline
\end{tabular}

\subsection{Testing the model at the level of whole Phragmites stands}

Testing the validity of the model requires reed stands which differ only by their PMR, but are affected by the same wave + drifting matter energy input. Then, the DMD should depend only on the PMR, i.e. it should be correlated with $\Sigma M_{\mathrm{E}, i}$ and $\Sigma M_{\mathrm{S}, i}$ (see Eq. 5). An adequate situation was found only in the Phragmites stand MOD III, where 20 test plots were examined. The culms were grouped into the classes undamaged $(A+B)$ and damaged $(C+D)$.

A significant correlation ( $r$, Pearson's correlation coefficient) was found between the percentage of damaged culms (DMD ${ }_{\text {stems }}$ ) and the $\sum M_{\mathrm{E}, i}$ and $\sum M_{\mathrm{S}, i}$ values

$$
\mathrm{DMD}_{\text {stems }}=505.5-\ln \left(\sum M_{\mathrm{E}, i}\right) ; \quad r=-0.748, n=20, \alpha<0.001
$$




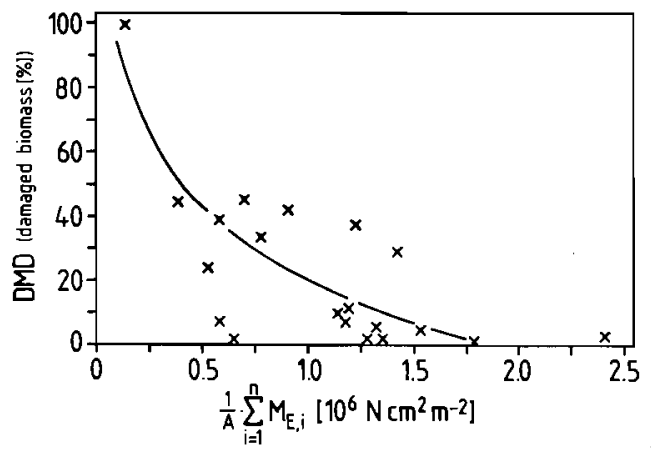

Fig. 5. Test of the PMR model at the level of reed stands: correlation between the $\mathrm{DMD}_{\text {biomass }}$ (percentage of damaged biomass) within the test stand MOD III and $\Sigma M_{\mathrm{E}, i}$ (sum of bending momentum values of individual stems within this test plot) (see text for explanations).

$$
\mathrm{DMD}_{\text {stems }}=393.2-\ln \left(\sum M_{\mathrm{S}, i}\right) ; \quad r=-0.646, n=20, \alpha<0.01
$$

Similar highly significant correlations apply to the percentage of damaged biomass (dry matter, stems + leaves). DMD $_{\text {biomass }}$ is regarded (Fig. 5) as

$$
\begin{aligned}
& \mathrm{DMD}_{\text {biomass }}=474.7-\ln \left(\sum M_{\mathrm{E}, i}\right) ; \quad r=-0.820, n=20, \alpha<0.001 \\
& \mathrm{DMD}_{\text {biomass }}=377.9-\ln \left(\sum M_{S, i}\right) ; \quad r=-0.726, n=20, \alpha<0.001
\end{aligned}
$$

The model explains $42 \%$ and $56 \%$ of the variability of $\mathrm{DMD}_{\text {stems }}$, and $53 \%$ and $67 \%$ of the variability of $\mathrm{DMD}_{\text {biomass }}$, respectively.

\section{Discussion}

The common reed, Phragmites australis, colonises the shorelines of a wide range of lakes, canals, rivers, estuaries and brackish waters. It is generally assumed that, at least for larger open water places, the outermost reed front is in equilibrium with the mechanical impact by waves and drifting matter, i.e. that the yearly amount of biomass destroyed by these forces is equal to the yearly biomass increment the stand would have in a mechanically unaffected state (e.g. Ostendorp, 1992; Fig. 3). Owing to its power of mechanical resistance, Phragmites australis is frequently used in biological waterways engineering to damp the wave amplitude and to protect the banks from being eroded (Bittmann, 1953, 1968; Bonham, 1983).

There are, however, examples from the literature indicating that storm or ship-induced wave action and drifting matter is to a large degree responsible for the reed decline in many central European lakes (Ostendorp, 1989), demonstrating that the power of mechanical resistance of lakeside reeds can be exceeded. An alternate hypothesis to explain the dieback of reed was put forward by Klötzli (1971). He claimed that eutrophic Phragmites reeds produce weaker culms, which leads to a frequent failing under mechanical stress and to a 'matting' of the reedbeds. Raghi-Atri and Bornkamm (1980) took over this idea. In fertil- 
isation experiments with Phragmites australis they found that the tensile strength and the proportion of sclerenchyma tissue per square millimetre of stem cross section area were negatively correlated with nitrogen. They did not, however, propose a model that permits estimation of the effect of this loading under field conditions.

The mechanical damage to a reed stand leads to a loss of culms and photosynthesising biomass, as described in Section 4.2. It can be assumed that the negative effects on the reed stand as a total will be proportional to the percentage of damaged or lost culms and that, as a threshold value is surpassed, the stand will visibly deteriorate, this being the beginning of the decline process. As an example, summer cutting experiments have shown a reduced biomass in the subsequent season (Gallagher, 1983; Steinmann and Brändle, 1984; Giroux and Bédard, 1987). However, detailed observations, covering a number of years, are not available. In this paper the power of mechanical resistance as a passive property of the reed stand is focused upon, taking no account of wave energy distribution at the reed front, nor of the kind and quantity of drifting matter and the interactive forces of waves, drifting matter and reed culms. By this model it is possible to compare the resistance of two Phragmites stands against an unknown, but constant, impact of drifting matter powered by waves. The input variables are the mechanical properties (bending stiffness, or breaking stress), the geometric properties of the stem cross section (both variables measured at that stem height, at which bending or breaking normally occurs) and the culm density of the stand.

The model described in Section 4.3 implies that, if the external mechanical impacts are constant, the proportion of culms that fail will be inversely proportional to the sum of the bending stiffness values (or breaking momentum) of individual culms per square metre. It is. however, expensive and time consuming to prove the equality of energy input as the damaging event takes place: the measurement of wave energy input requires platforms in front of selected reed stands, and data recording equipment (e.g. Piroth and Plate, 1993, pp. 85-87) installed to await an adequate storm on the lake. It was not possible to simulate wind driven waves by ship induced waves (e.g. Bonham, 1983; Huber and Weiss, 1986), as most reed areas are situated within nature reserves, and because the water depth of the littoral platform was too shallow to allow navigation by big vessels. Another possibility to test the model was pursued here: to find a uniform shore section affected by waves coming in at a right angle to the reed front, and transporting drifting matter, whose mass should not vary along the shoreline. Hence, alongshore variation of the percentage of damaged culms should only be due to differences in PMR.

The pmr model was tested at the level of individual culms. It explains up to $90 \%$ of all cases ( upright vs. broken culms). At the level of whole Phragmites stands, the PMR model explains up to $56 \%$ of the variability of the proportion of damaged culms and up to $67 \%$ of the variability of damaged biomass. These relatively low figures are attributed to the fact that longshore variability of wave + drifting matter energy cannot be neglected. It is assumed that, in reality, the front culms protect the culms at a short distance behind, so that the test plots comprise 'protected' and 'unprotected' culms in variable proportions. This would mean that the assumptions of the test are not perfectly fulfilled.

Several countermeasures have been taken against the damage to lakeside reeds by waves + drifting matter (Ostendorp et al., 1995). One was intended to improve the power of mechanical resistance of the reeds by biomanipulation. Along with the findings of RaghiAtri and Bornkamm (1980), winter cutting was performed to reduce the nutrient and organic 
matter load of the reed beds. Winter cut Phragmites stands had thinner stems with unfavourable mechanical properties at high densities, so that their PMR was lessened. Field observations confirmed that the kind of management was responsible for a high degree of damage to treated reeds (Ostendorp, 1995). In other instances, reed planting has been considered. It must be ensured that the new Phragmites stands will not be overcharged mechanically. This includes testing the clones for their mechanical properties, and monitoring development of the stand structure, until the newly planted stand is fully grown.

The model presented in this paper opens up possibilities to make realistic estimates of the potential resistance of reeds to mechanical load. It provides the means to investigate the influence of various ecological factors (e.g. eutrophication, see Ostendorp, 1990) on the mechanical stability of fringing reeds, and to select the best suited clone or an optimum management or reed protection strategy to avoid reed bed losses due to mechanical damage.

\section{Acknowledgements}

The author is indebted to H.R. Binz who introduced him into the measuring procedure, and to S. Schroeder for linguistic improvements.

\section{References}

Binz-Reist, H.-R., 1989. Mechanische Belastbarkeit natürlicher Schilfbestände durch Wellen, Wind und Treibzeug. Veröff. Geobot. Inst. ETH Zürich, 101: 536 pp.

Bittmann, E., 1953. Das Schilf (Phragmites communis Trin.) und seine Verwendung im Wasserbau. Angew. Pflanzensoziol. (Stolzenau), 7: 1-41.

Bittmann, E., 1968. Lebendbaumassnahmen an Still- und Fliessgewässem mit Ausnahme von Wildbächen. In: K. Buchwald and W. Engelhardt (Editors), Handbuch für Landschaftspflege und Naturschutz, Vol. 4, München, Bayrischer Landwirtschaftsverlag, pp. 158-172.

Bonham, A.J., 1983. The management of wave-spending vegetation as bank protection against boat wash. Landscape Plann., 10: 15-30.

Brändle, R., 1991. Flooding resistance of rhizomatous amphibious plants. In: M.B. Jackson, D.D. Davies and H. Lambers (Editors), Plant Life under Oxygen Deprivation. SPB, The Hague, pp. 35-46.

Carter, R.W.G., 1988. Coastal Environments. An Introduction to the Physical, Ecological and Cultural Systems of Coastline. Academic Press, London, 617 pp.

Gallagher, J.L., 1983. Seasonal pattern in recoverable underground reserves in Spartina atterniflora Loisel. Am. J. Bot., 70: 212-215.

Giroux, J.-F. and Bédard, J., 1987. Effects of simulated feeding by snow geese in Scirpus americanus rhizomes. Oecologia, 74: 137-143.

Huber, A. and Weiss, H.W., 1986. Wellenerosion am Rhein. Wasser, Energie, Luft, 78: 205-211.

Klötzli, F., 1971. Biogenous influence on aquatic macrophytes especially Phragmites communis. Hidrobiologia (Bucaresti), 12:172-181.

Lang, G., 1967. Die Ufervegetation des westlichen Bodensees. Arch. Hydrobiol. Suppl., 32: 437-574.

Lang, G., 1981. Die submersen Makrophyten des Bodensees-I978 im Vergleich mit 1967. Berichte der Internationalen Gewässerschutzkommission für den Bodensee 26, 64 pp.

Lang, G.; 1990. Die Vegetation des westlichen Bodenseegebietes. G. Fischer, Stuttgart, 462 pp.

Ostendorp, W., 1989. 'Die-back' of reeds in Europe-a critical review of literature. Aquat. Bot., 35: 5-26.

Ostendorp, W., 1990. Ist die Seeneutrophierung am Schilfsterben schuld? In: H. Sukopp and M. Krauss (Editors), Ökologie, Gefährdung und Schutz von Röhrichtpflanzen. Landschaftsentwicklung und Umweltforschung (Berlin), $71: 121-140$. 
Onedorp, W., 1991. Zur Geschichte der Uferröhrichte des Bodensee-Untersees. Schriftenr. Ver. Geschichte Bodensees Umgebung, 109: 215-233.

Ostendorp. W., 1992. Shoreline algal wash as a factor in reed decline in Lake Constance-Untersee. Hydrobiologia, 242: $165-174$.

Ostendorp. W., 1995. Effect of management on the mechanical resistance of lakeside reeds in Lake Constance. Acta Oecologica, in press.

Ostendorp. W., Iseli, Chr., Krauss, M., Krumscheid-Plankert, P., Moret, J.-L., Rollier, M. and Schanz, F., 1995. Lake shore deterioration, reed management and bank restoration in some Central European lakes. In: W.J. Mitsch (Editor), Constructed and Restored Wetlands. Ecol. Eng. (Special Issue) (accepted).

Piroth. K. and Plate, E., 1993. The wave climate, an important factor in lakeshore deterioration-concept and measurements at Lake Constance. In: W. Ostendorp and P. Krumscheid-Plankert (Editors), Seeuferzerstörung und Seeuferrenaturierung. Limnol. Aktuell, 5: 77-92.

Raghi-Atri, F. and Bornkamm, R., 1980. Über Halmfestigkeit von Schilf (Phragmites australis) bei unterschiedlicher Nährstoffversorgung. Arch. Hydrobiol., 90: 90-105.

Rodewald-Rudescu, L., 1974. Das Schilfrohr-Phragmites australis Trin. Die Binnengewässer, 27: I-302.

Steinmann, F. and Brändle, R., 1984. Auswirkungen von Halmverlusten auf den Kohlehydratstoffwechsel überfluteter Seebinsenrhizome (Schoenoplectus lacustris (L.) Palla). Flora, 175: 295-299.

Studer. Ch. and Brändle, R., 1984. Sauerstoffkonsum und Versorgung der Rhizome von Acorus calamus L., Glyceria maxima (Hartm.) Holmberg, Menyanthes trifoliata L., Phalaris arundinacea L., Phragmites communis Trin. and Typha latifolia L. Bot. Helvet., 94: 23-31. 